\title{
Prevalence and predictors of burnout syndrome, post-traumatic stress disorder, depression, and anxiety in nursing staff in various departments
}

\author{
Rania A. Hamed ${ }^{1 *}$ (D), Shaimaa Y. Abd Elaziz ${ }^{1}$ and Amani S. Ahmed²
}

\begin{abstract}
Background: Hospital settings are a highly challenging work environment because of the increased demands of most of the works assigned to do, changes in the everyday routine of work, unreasonable expectations of patients and their relatives, and serious legal and death problems. Nurses experience stress due to work exhaustion that makes them vulnerable to many psychiatric disorders. This study aimed to assess the prevalence of burnout syndrome, post-traumatic stress disorder, depression, and anxiety in nursing group and their possible risk factors. A cross-sectional study was conducted among 181 nurses working at Al Zahraa University Hospital, Cairo, Egypt; the sociodemographic characteristics and occupational data were collected and Hospital Anxiety Depression Scale, Davidson Trauma Scale, Maslach Burnout Inventory, and Proactive Coping Inventory were completed.

Results: Psychiatric symptoms were prevalent among nurses, 79\% were positive for depression and $64.6 \%$ were positive for anxiety. The prevalence of post-traumatic stress disorder was $19.9 \%$, while $87.8 \%$ of nurses were positive for burnout syndrome and had symptoms for at least one of the 3 types of burnout syndrome: $73.5 \%$ for emotional exhaustion, $61.9 \%$ for depersonalization, and $68.5 \%$ for personal accomplishment. Eighty-six percent of nurses who had post-traumatic stress disorder were also positive for burnout syndrome. ICU nurses had 100\% emotional exhaustion symptoms compared with other departments; lack of use of different coping approach towards stressors at work and work experience was risk factors of burnout syndrome.
\end{abstract}

Conclusion: Burnout syndrome, post-traumatic stress disorder, depression, and anxiety were common in a wide group of nurses; the development of health educational program for nurses about different coping strategies to face stressors and conflicts at work is mandatory.

Keywords: Burnout syndrome, Post-traumatic stress disorder, Depression, Anxiety, Nurses

\section{Background}

Hospital settings are a highly challenging work environment because of the increased demands of most of the works assigned to do, changes in the everyday routine of work, unreasonable expectations of patients and their relatives, and serious legal and death problems [1].

\footnotetext{
* Correspondence: drrania96@gmail.com

'Department of Psychiatry, Faculty of Medicine for Girls, Al-Azhar University, Cairo, Egypt

Full list of author information is available at the end of the article
}

Nurses experience stress due to work exhaustion that makes them vulnerable to many psychiatric disorders such as burnout syndrome (BOS) and post-traumatic stress disorder (PTSD) [2]. It includes feelings of emotional exhaustion, depersonalization, and decreased personal accomplishment in the workplace [3]. BOS is characterized by long-term job stress arising from the relationship between persistent emotional pressure together with strong interpersonal engagement over extended time periods and depending on personal traits 
[4]. Burnout syndrome is especially high among service and cure staff, especially those involved in health and care [4]. Among these, nurses were the subject of many studies, a survey carried out in Europe (2011) revealed that about $30 \%$ of nursing staff reported being exhausted or tired as a result of work activities [5]. Burnout syndromes are prevalent in nurses, particularly those working in intensive care units [6]. In addition, nurses especially critical care nurses are regularly subjected to stresses such as tackling the end of life needs, doing cardiopulmonary resuscitation, and postmortem care. This can contribute to the risk of occurrence of serious psychiatric disorders such as PTSD, depression, or anxiety [7].

Individuals establish various ways of coping with a stressful situation based on individual variables, situational requirements, and the available facilities intending to rebuild the individual well-being against the hazardous consequences of stressors. From this perspective, the coping strategies used by nurses facing work-related stresses have gained significant attention [8].

However, only few researches have determined the prevalence of BOS and PTSD in Egyptian nurses, so the purpose of this research was to obtain a full psychological evaluation of nursing-related BOS, PTSD, depression, and anxiety in order to resolve these issues and how these nurses react to the work stressors by using various coping strategies.

\section{Methods}

This study was a cross-sectional one; it was conducted among nurses at $\mathrm{Al}$ Zahraa University Hospital, Cairo, Egypt, over the period from January to December 2018. The target population was all nurses working at $\mathrm{Al}$ Zahraa University Hospital either males or females who were full-time nursing working for at least 1 year who have no past history of any psychiatric, neurological, or medical illness that could affect psychological condition prior to beginning of their hospital work. The number of nurses was 287 nurses, and only 181 nurses filled out the questionnaires, with overall $63.06 \%$ response after excluding incompletely filled ones, part time nurses, those working for less than 1 year, or having past history of any psychiatric, neurological, or medical illness that could affect psychological condition.

Nurses were divided into four groups: intensive care unit nurses $(N=25)$, inpatient nurses in stressful areas (non-intensive care unit) $(N=54)$, inpatient nurses (non-stressful areas) $(N=78)$, and outpatient nurses $(N=24)$. Non-intensive care unit stressful areas included the obstetric unit, the burning unit, and the emergency unit.

All nurses included in the study were subjected to the following:
1- Collection of sociodemographic data and information about the work environment including age, marital status, work department, experiences (in years), patient/nurses ratio, nurses' cooperation in patients' care, and the importance of the care of the nurse in patients' prognosis. Also, nurses' reliability in other nurses and nurses' reliability in physicians were measured by 4-point Likert response questions $(1=$ no trust to $4=$ high trust $)$.

2- Hospital Anxiety Depression Scale (HADS) [9], Arabic version [10]: it is a self-report scale used to explore the existence of depression and anxiety in medical, non-psychiatric settings. It includes 2 subscales: anxiety subscale and depression subscale, and a score $>8$ indicates the presence of depression and/or anxiety.

3- Davidson Trauma Scale (DTS) [11], Arabic version [12]: it is a self-report diagnostic scale that evaluates PTSD. Items are rated from $(0=$ not at all to $4=$ everyday) and subdivided into 3 subscales: reexperiences, avoidance, and hyperarousal.

4- Maslach Burnout Inventory (MBI) [13], Arabic version [14]: it is a self-report diagnostic scale consisting of three dimensions: emotional exhaustion (EE), depersonalization (DP), and personal accomplishment (PA). We scored participants as having BOS with emotional exhaustion, 17; depersonalization, 7; and personal accomplishment, 31 .

5- Proactive Coping Inventory (PCI) [15], Arabic version [16]: it is a self-report scale constructed to assess the different dimensions of proactive coping approach. It consists of seven subscales with different score ranges: proactive coping (14-56) "It combines autonomous goal setting with self-regulatory goal attainment cognitions and behavior," preventive coping (10-40) "It deals with anticipation of potential stressors and the initiation of preparation before these stressors develop fully," reflective coping (11-44) "It describes simulation and contemplation about a variety of possible behavioral alternatives," strategic planning (4-16) "It focuses on the process of generating a goal-oriented schedule of action in which extensive tasks are broken down into manageable components," instrumental support seeking (832) "It focuses on obtaining advice, information and feedback from people in one's social network when dealing with stressors," emotional support seeking (5-20) "It aimed at regulating temporary emotional distress by disclosing to others feelings, evoking empathy and seeking companionship from one's social network," and avoidance coping (3-12) "It eludes action in a demanding situation by delaying." 


\section{Statistical analysis}

The Statistical Package for Social Sciences (SPSS version 21.0) was used for data entry and analysis. Qualitative data were described in the form of numbers and percentages; $\chi^{2}$ test or Fisher's exact test was used to test for the association between categorical variables, as appropriate. Quantitative data were described as mean and standard deviation (mean $\pm \mathrm{SD}$ ) and after testing for normality by Kolmogorov-Smirnov; ANOVA test was used for comparison between more than two groups normally distributed and nonparametric Kruskal-Wallis test for more than two groups not normally distributed data.

Binary logistic regression analysis was used for prediction of independent variables of burnout syndrome, post-traumatic stress disorder, depression, and anxiety. Significant variables in the bivariate analysis were used into the regression model. Crude (COR) and adjusted odds ratios (AOR) and their 95\% confidence intervals (95\% CI) were calculated. $P$ value $\leq .05$ was considered to be statistically significant.

\section{Results}

Table 1 shows that the nurses were predominantly females. Comparison between the 4 groups shows statistical significance in age, experiences in years, pt/nurses ratio, and marital status.

Graph 1 shows that all groups of nurses had prevalent psychiatric symptoms, $79 \%$ (143) were positive for depression and $64.6 \%$ (117) were positive for anxiety. As regards PTSD, 19.9\% (36) of nurses had PTSD symptoms based on Davidson Trauma Scale. A total of $87.8 \%$ (159) of nurses were positive for BOS and had symptoms for at least one of the 3 types of BOS: $73.5 \%$ (133) for emotional exhaustion, 61.9\% (112) for depersonalization, and $68.5 \%$ (124) for personal accomplishment. Overall,
88.4\% (160) of nurses had depression, anxiety, posttraumatic stress disorder, or burnout syndrome.

No significant differences in depression, anxiety, or PTSD were found among the 4 nurses groups. However, the prevalence of BOS (emotional exhaustion symptoms) showed significant difference between them (Graph 2).

Table 2 shows that $86 \%$ (31 out of 36 ) of nurses who had PTSD were also positive for burnout syndrome. However, only $19.49 \%$ (31 out of 159) of nurses who were positive to BOS also had the criteria for PTSD diagnosis. The group of nurses was then divided into 4 groups: nurses with BOS and no PTSD $(N=128)$, nurses with BOS and PTSD $(N=31)$, nurses without BOS nor PTSD $(N=$ $17)$, and nurses with PTSD and no BOS $(N=5)$.

Comparing the age of the four groups of nurses shows statistical significance: nurses with BOS and no PTSD (38 \pm 9.91 years), nurses with BOS and PTSD (36.61 \pm 10.21 years), nurses without BOS nor PTSD (45.52 \pm 10.51 years), nurses with PTSD and no BOS (37.4 \pm 12.46 years), $P=0.02$. Regarding their experience in years: those with BOS alone (18.68 \pm 9.8 years), those with both BOS and PTSD (17.64 \pm 10.7 years), those with neither BOS nor PTSD (26.7 \pm 9.6 years), and those with PTSD alone (18 \pm 12.84 years), $P=0.01$. Also, there was significant difference in "The importance of the care of the nurse in patients' prognosis" $(P=0.01)$. There was no difference in the "Nurses' reliability in other nurses," "Nurses' reliability in physicians," and "Nurses' cooperation in patients' care."

Table 3, multivariate logistic regression analysis, showed the independent risk factors of burnout syndrome, post-traumatic stress disorder, depression, and anxiety in nursing staff were lack of use of different coping approach towards stressors at work. Risk factors of burnout syndrome were lack of use of proactive coping

Table 1 Sociodemographic and work characteristics of the studied groups

\begin{tabular}{|c|c|c|c|c|c|c|}
\hline & $\begin{array}{l}\text { Intensive care unit } \\
\text { nurses }(N=25)\end{array}$ & $\begin{array}{l}\text { Inpatient nurses in stressful } \\
\text { areas }(N=54)\end{array}$ & $\begin{array}{l}\text { Inpatient nurses } \\
\text { (non-stressful } \\
\text { areas) }(N=78)\end{array}$ & $\begin{array}{l}\text { Outpatient nurses } \\
(N=24)\end{array}$ & Total $(N=181)$ & $P$ value \\
\hline Age (in years) $X \pm S D$ & $32.04 \pm 9.18$ & $36.42 \pm 7.92$ & $40.24 \pm 10.51$ & $43.91 \pm 11.24$ & $38.45 \pm 10.27$ & $<0.001^{(1)}$ \\
\hline Experiences (in years) $X \pm S D$ & $11.68 \pm 8.18$ & $17.88 \pm 7.38$ & $20.78 \pm 10.36$ & $25.16 \pm 11.99$ & $19.24 \pm 10.17$ & $<0.001^{(1)}$ \\
\hline Patient/nurses $X \pm S D$ & $5.2 \pm 2.41$ & $8.9 \pm 5.66$ & $13.16 \pm 7.48$ & $25.9 \pm 17.41$ & $12.48 \pm 10.4$ & $<0.001^{(1)}$ \\
\hline \multicolumn{7}{|l|}{ Gender } \\
\hline Female N (\%) & $23(92 \%)$ & $50(92.6 \%)$ & 76 (97.4\%) & $20(83.3 \%)$ & $169(93.4 \%)$ & $>0.05^{(2)}$ \\
\hline Male N (\%) & $2(8 \%)$ & $4(7.4 \%)$ & $2(2.6 \%)$ & $4(16.7 \%)$ & $12(6.6 \%)$ & \\
\hline \multicolumn{7}{|l|}{ Marital status } \\
\hline Single $N(\%)$ & $5(20 \%)$ & $5(9.3 \%)$ & $6(7.7 \%)$ & $1(4.2 \%)$ & $17(9.4 \%)$ & $0.05^{(2)}$ \\
\hline Married N (\%) & $20(80 \%)$ & $47(87 \%)$ & 67 (85.9\%) & $18(75 \%)$ & $152(84.1 \%)$ & \\
\hline Divorced N (\%) & $0(0 \%)$ & $2(3.7 \%)$ & $0(0 \%)$ & $0(0 \%)$ & $2(1.1 \%)$ & \\
\hline Widow N (\%) & $0(0 \%)$ & $0(0 \%)$ & $5(6.4 \%)$ & $5(20.8 \%)$ & $10(5.5 \%)$ & \\
\hline
\end{tabular}

Kruskal-Wallis test ${ }^{(1)}$, Fisher's exact test ${ }^{(2)}$ 


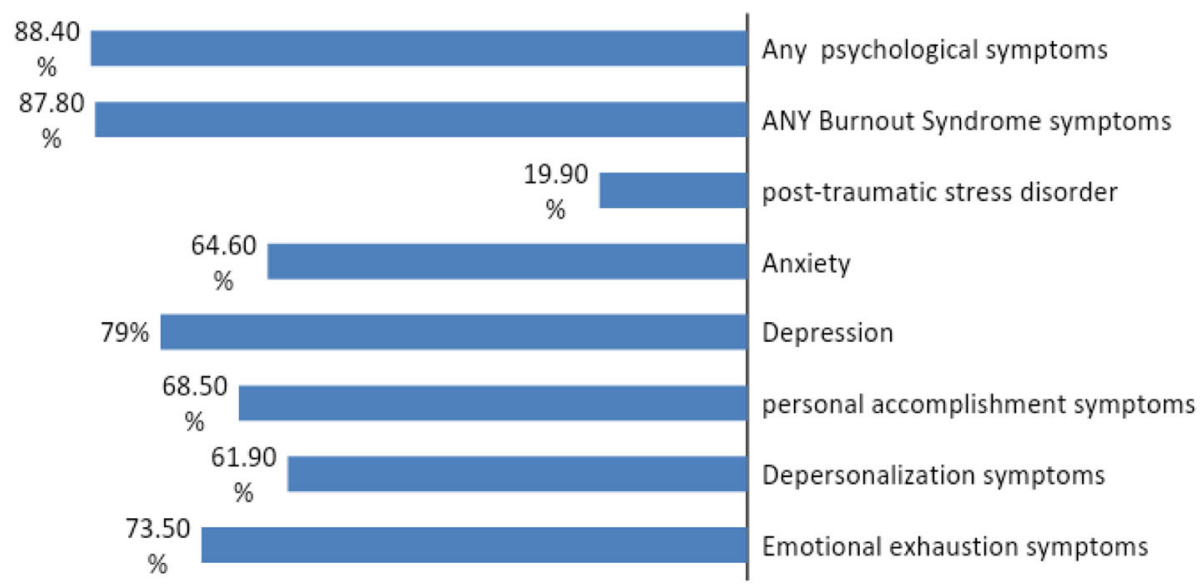

Graph 1 The overall prevalence of psychiatric disorders and burnout syndrome among the studied groups

and instrumental support seeking with AOR [95\% CI] of 0.86 [0.81-0.91] and 0.93 [86-97], while increasing age and experience act as protective factors for burnout syndrome with AOR [95\% CI] of $92[0.85-0.98]$ and 0.8 [0.54-0.97]. Lack of use of reflective coping, preventive coping, instrumental support seeking, and emotional support seeking was the risk factors of depression with AOR [95\% CI] of 0.58 [0.37-0.91], 0.5 [0.27-0.94], 0.34 [0.11-0.98], and 0.02 [0.02-0.85] respectively. Defective reflective coping and preventive coping were risk factors for anxiety with AOR [95\% CI] of 0.93 [0.87-0.99] and 0.91 [0.84-0.99], while defective avoidance coping and instrumental support seeking were risk factors of posttraumatic stress disorder with AOR $[95 \% \mathrm{CI}]$ of 0.8
[0.65-0.99] and 0.9 [0.84-0.99]. Overall, Proactive Coping Inventory scale is a predictor for burnout syndrome, post-traumatic stress disorder, depression, and anxiety

\section{Discussion}

In our study, we find that burnout syndrome, posttraumatic stress disorder, depression, and anxiety are prevalent in nursing groups. The BOS has been thoroughly studied as it has a detrimental effect on nurses suffering from it by raising their absence and medical errors that have direct impact on patient safety in addition to its effect on the health institution itself $[17,18]$.

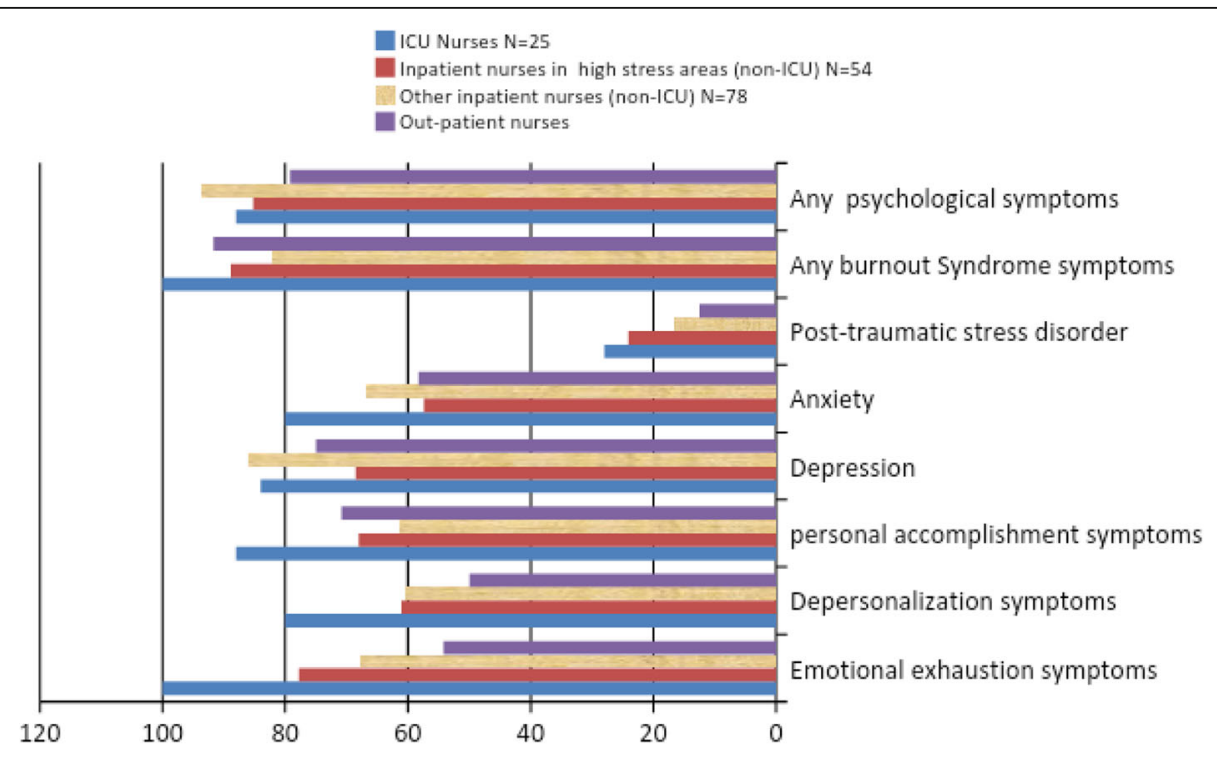

Graph 2 The prevalence of psychiatric disorders and burnout syndrome among the studied nurses in different departments. Emotional exhaustion symptoms showed statistically significant difference among the four groups $(P$ value $<0.01)$ by Fisher's exact test, and no statistically significant difference in the other parameters $(P$ value $>0.05)$ by whether $x^{2}$ test or Fisher's exact test 
Table 2 Comparison between nurses diagnosed with/without burnout syndrome and/or post-traumatic stress disorder

\begin{tabular}{|c|c|c|c|c|c|}
\hline & $\begin{array}{l}\text { Nurses with burnout } \\
\text { syndrome and no post- } \\
\text { traumatic stress disorder } \\
(N=128)\end{array}$ & $\begin{array}{l}\text { Nurses with burnout } \\
\text { syndrome and post- } \\
\text { traumatic stress disorder } \\
(N=31)\end{array}$ & $\begin{array}{l}\text { Nurses without } \\
\text { burnout syndrome } \\
\text { not post-traumatic } \\
\text { stress disorder }(N=17)\end{array}$ & $\begin{array}{l}\text { Nurses with post-traumatic } \\
\text { stress disorder and no } \\
\text { burnout syndrome }(N=5)\end{array}$ & $P$ value \\
\hline Gender (female) $N(\%)$ & $119(92.9 \%)$ & $30(96.7 \%)$ & $15(88.2 \%)$ & $5(100 \%)$ & $0.63^{(1)}$ \\
\hline Age in years $(X \pm S D)$ & $38 \pm 9.91$ & $36.61 \pm 10.21$ & $45.52 \pm 10.51$ & $37.4 \pm 12.46$ & $0.02^{(2)}$ \\
\hline Experience in years $(X \pm S D)$ & $18.68 \pm 9.8$ & $17.64 \pm 10.7$ & $26.7 \pm 9.6$ & $18 \pm 12.84$ & $0.01^{(3)}$ \\
\hline Patient/nurses $(X \pm S D)$ & $12.42 \pm 11.03$ & $11.22 \pm 10.04$ & $13.58 \pm 6.78$ & $18.2 \pm 2.94$ & $0.54^{(3)}$ \\
\hline $\begin{array}{l}\text { Nurses' reliability in other } \\
\text { nurses }(X \pm S D)\end{array}$ & $3.7 \pm 0.59$ & $3.64 \pm 0.8$ & $3.64 \pm 0.49$ & $3.8 \pm 0.44$ & $0.62^{(3)}$ \\
\hline $\begin{array}{l}\text { Nurses' reliability in } \\
\text { physicians }(X \pm S D)\end{array}$ & $3.77 \pm 0.45$ & $3.61 \pm 0.61$ & $3.47 \pm 0.62$ & $3.6 \pm 0.54$ & $0.06^{(3)}$ \\
\hline $\begin{array}{l}\text { Nurses' cooperation in } \\
\text { patients' care } N(\%)\end{array}$ & $122(95.3 \%)$ & $26(83.9 \%)$ & $16(94.1 \%)$ & $5(100 \%)$ & $0.12^{(1)}$ \\
\hline $\begin{array}{l}\text { The importance of the } \\
\text { care of the nurse in } \\
\text { patients' prognosis } N(\%)\end{array}$ & $127(99 \%)$ & $28(90.3 \%)$ & $14(82.4 \%)$ & $5(100 \%)$ & $0.01^{(1)}$ \\
\hline
\end{tabular}

Fisher's exact test ${ }^{(1)}$, ANOVA test ${ }^{(2)}$, Kruskal-Wallis test ${ }^{(3)}$

Our study shows that emotional exhaustion is the most affected aspect of BOS in nurses, being present in $73.5 \%$ of the sample. This is followed by personal accomplishment, which was found in $68.5 \%$ of the sample. The lowest level was depersonalization, which affected $61.9 \%$ of these nurses. This was in agreement with Elshaer et al. [19] who found that the most of the study subjects developed high emotional exhaustion scores $(80 \%)$, while $<1 / 3$ reported either high depersonalization or low personal accomplishment levels.

It is worthy to mention that the predominance of female nurses in our sample could add to the burden of stress at work place for them and this is in line with the study done in Ethiopia and found significantly association between sex and job stress [20]. Female nurses are more subjected to different sources of stress such as discrimination, stereotyping in addition to coordination between work, and marriage and family demands.

Among these 3 dimensions of BOS, ICU nurses had the highest prevalence compared to inpatient nurses in stressful areas (non-ICU), inpatient nurses (non-intensive care unit), and outpatient ones. This can be explained that ICU nurses encounter difficult patients facing life issues forcing them to meet daily challenges that add more pressure to their work.

These results are in concordance with the study of Gillespie and Melby [21] who studied BOS on nursing staff in accident, emergency, and acute medicine departments and reported the same results. Another study of the prevalence of BOS and PTSD in nurses at the University of Colorado Hospital revealed that the highest stress facing nurses were the patient's death and seeing a patient suffer as death is usually linked to clinical failure [1].
From multitude of researches, $25-33 \%$ of ICU nurses develop severe BOS and approximately $86 \%$ have at least 1 symptom out of the 3 symptoms of BOS [22, 23, 28].

Another study done by Poncet et al. [24] on critical care nurses revealed severe BOS in $32.8 \%$ of participants similarly to the study of Verdon et al. [25] who reported that third of the critical care nurses developed BOS.

Nurses diagnosed with PTSD almost develop BOS, but the reverse is not always fulfilled, as just $19.49 \%$ of nurses with BOS were diagnosed with PTSD. These refer to the fact that nurses who develop PTSD will be vulnerable to BOS.

Also, the combination of both diagnosis of BOS and PTSD has significant relation with how the care received by the nurses is one of the key factors in the prognosis of the patient. Moreover, nurses without BOS and PTSD are elder and have more years of experience compared to those with both BOS and PTSD. Similarly, the analysis of job-related stress among nurses employed in Ethiopia correlated years the nurse had practiced and her age with the prevalence of PTSD [26]. This can be explained that the adaptation and coping of nurses become better and effective overtime.

In our study, $79 \%$ were positive for depression and $64.6 \%$ were positive for anxiety. These results are in concordance with a study of held in Australia that concluded that depression levels were predicted significantly by the level of stress nurses are exposed to [27].

Our study reveals that increasing age and experience act as a protective factors for burnout syndrome; this finding could be explained that nurses with more experience on their job may gain higher confidence about tasks they do, and may make relationships at work that are meaningful to them [28]. In coherence with these findings, Patrick and Lavery [29] reported that nurses 


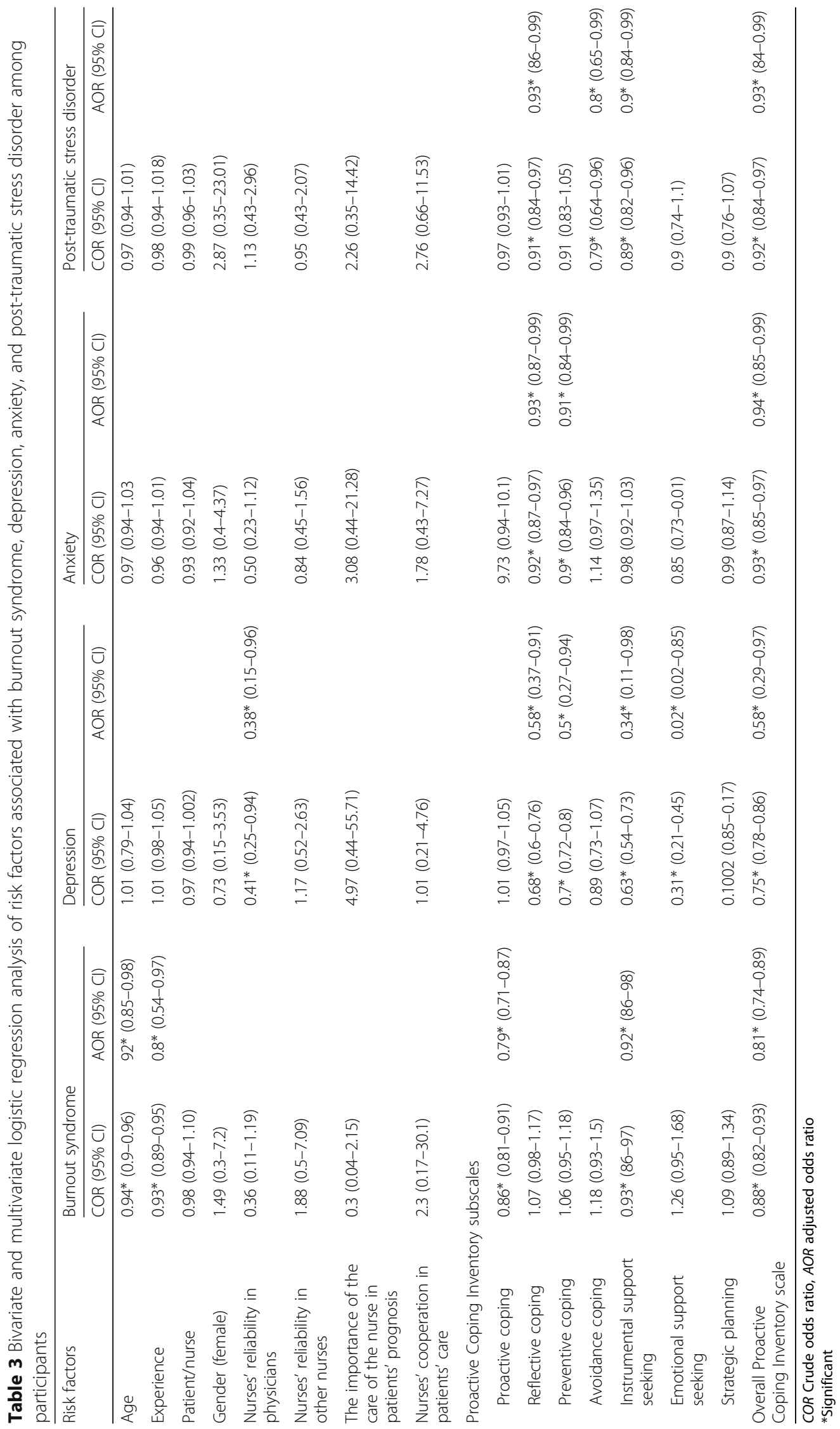


who work longer duration on the job are more likely to have experienced almost all work scenarios. Another explanation could be that nurses in this sector have less working hours or their job nature changed with more on desk tasks than working closely to patients which lead to less burden on older nurses. In the present study, risk factors of burnout syndrome were lack of use of proactive coping and instrumental support seeking. These results are in concordance with a study on the relationship between proactive coping and the different three dimensions of burnout that found that nurses with a more proactive coping style had experienced less symptoms of burnout [30].

In the present study, lack of use of reflective coping and preventive coping was risk factors of both depression and anxiety, while defective avoidance coping and instrumental support seeking were risk factors of posttraumatic stress disorder .Overall proactive coping inventory scale is a predictor for burnout syndrome, posttraumatic stress disorder, depression, and anxiety. These findings are in concordance with a study on proactive coping and PTSD among nursing students in which regression analysis revealed that proactive coping was associated with lower levels of PTSD, depression, and anxiety [31]. In contrast to a Chinese study which reported that although the study participants had successful coping mechanisms, yet they had significant levels of stress and depression [32].

Proactive individuals often make efforts to plan in advanced manner that allow them more easily to overcome distress and challenging goals and to promote their personal growth [26]. Proactive individuals are considered future oriented and they know how to use their resources to face stressors before being emotionally exhausted. So, they are more likely to set up resources that serve as buffers against stress and are less likely to accumulate stress to a level that cannot be handled.

\section{Conclusion}

BOS, PTSD, and other psychological symptoms were common in a wide group of nurses; the development of instituting strategies and health educational program for nurses about different coping strategies may hold promise for reducing conflict that nurses face during their job and further interventional studies need to be conducted in this issue.

\footnotetext{
Abbreviations

BOS: Burnout syndrome; PTSD: Post-traumatic stress disorder; ICU: Intensive care unit; HADS: Hospital Anxiety Depression Scale; DTS: Davidson Trauma Scale; MBI: Maslach Burnout Inventory; PCl: Proactive Coping Inventory; SPSS: Statistical Package for Social Sciences
}

\section{Acknowledgements}

The authors wish to express their gratitude to all nurses for their taking part in this study.

\section{Authors' contributions}

RAH designed the study and was a major contributor in writing the manuscript. SYA collected the patients' data and applied the scales. ASA analyzed and interpreted the patient data. All authors read and approved the final manuscript.

\section{Funding}

None

\section{Availability of data and materials Not applicable.}

\section{Ethics approval and consent to participate}

All participants were involved in this study after giving written informed consent. The study's purpose was explained and privacy of information was ensured. The study was done consistent with good clinical practice and Declaration of Helsinki and World Health Organization guidelines. The committee's reference number is 201907113.

\section{Consent for publication}

Not applicable.

\section{Competing interests}

The authors declare that they have no competing interests.

\section{Author details}

'Department of Psychiatry, Faculty of Medicine for Girls, Al-Azhar University, Cairo, Egypt. ${ }^{2}$ Community, Environmental and Occupational Medicine Department, Faculty of Medicine, Zagazig University, Zagazig, Egypt.

Received: 7 May 2020 Accepted: 30 June 2020

Published online: 01 September 2020

\section{References}

1. Mealer M, Burnham EL, Goode CJ, Rothbaum B, Moss M (2009) The prevalence and impact of post-traumatic stress disorder and burnout syndrome in nurses. Depr anx 26(12):1118-1126

2. Godoy MT, Bouttelet D (2004) Rethinking the care provided to nursing woman. J Hum Growth Dev 14:63-68

3. Montero-Marín J, García-Campayo J, Mera DM, Del Hoyo YL (2009) A new definition of burnout syndrome based on Farber's proposal. J Occup Med Toxicol 4(1):31

4. Ribeiro VF, Ferreira Filho C, Valenti VE, Ferreira M, de Abreu LC, de Carvalho TD, Xavier V, de Oliveira FJ, Gregory P, Leão ER, Francisco NG (2014) Prevalence of burnout syndrome in clinical nurses at a hospital of excellence. Int Arch Med 7(1):22

5. Galindo RH, Feliciano KV, Lima RA, Souza Al (2012) Burnout syndrome among general hospital nurses in Recife. Revista da Escola de Enfermagem da USP 46(2):420-427

6. Embriaco N, Azoulay E, Barrau K, Kentish N, Pochard F, Loundou A, Papazian $L$ (2007) High level of burnout in intensivists: prevalence and associated factors. Am j respir critic care med 175(7):686-692

7. Acker KH (1993) Do critical care nurses fave burnout, PTSD, or is it something else? AACN Clin Issues Crit Care Nurs 4:558-565

8. Laal M, Aliramaie N (2010) Nursing and coping with stress. Int J Collab Res Intern Med Public Health 2(5):15

9. Bjelland I, Dahl AA, Haug TT, Neckelmann D (2002) The validity of the Hospital Anxiety and Depression Scale: an updated literature review. J psychosomat res 52(2):69-77

10. Terkawi AS, Tsang S, AlKahtani GJ, Al-Mousa SH, Al Musaed S, AlZoraigi US et al (2017) Development and validation of Arabic version of the Hospital Anxiety and Depression Scale. Saudi j anaesthesia 11(Suppl 1):S11

11. Davidson JR, Book SW, Colket JT, Tupler LA, Roth S, David D, Hertzberg M, Mellman T, Beckham JC, Smith RD, Davison RM (1997) Assessment of a new self-rating scale for post-traumatic stress disorder. Psychol med 27(1):153-160

12. Arab Corporation for Psychological Tests. Arabic version of Davidson PTSD Scale according to DSM-IV. 2010. Available from: http://arabtesting.com/ : Personal communication with Dr. Abdel-Mawggod Abdel samiee head manager of Arab corporation for psychological test.

13. Maslach C, Schaufeli WB, Leiter MP (2001) Job burnout. Annu Rev Psychol 52:391-422 
14. Sabbah I, Sabbah H, Sabbah S, Akoum H, Droubi N. Burnout among Lebanese nurses (2012) psychometric properties of the Maslach burnout inventory-human services survey (MBI-HSS). Health 4(9):644-652.

15. Greenglass E, Schwarzer R, Jakubiec D, Fiksenbaum L, Taubert S (1999) The proactive coping inventory $(\mathrm{PCI})$ : a multidimensional research instrument. In20th International Conference of the Stress and Anxiety Research Society (STAR), Cracow, Poland 12:14.

16. Abdallah G \& Greenglass E (2005) The Proactive Coping Inventory (PClArabicVersion). Retrieved August 15, 2014, from www.psych.yorku.ca/ greenglass/.

17. Shanafelt TD, Balch CM, Bechamps G, Russell T, Dyrbye L, Satele D, Collicott P, Novotny PJ, Sloan J, Freischlag J (2010) Burnout and medical errors among American surgeons. Annals of surgery 251(6):995-1000

18. Teng Cl, Shyu Yl, Chiou WK, Fan HC, Lam SM (2010) Interactive effects of nurse-experienced time pressure and burnout on patient safety: a crosssectional survey. Intern j nurs studies 47(11):1442-1450

19. Elshaer NS, Moustafa MS, Aiad MW, Ramadan MI (2018) Job stress and burnout syndrome among critical care healthcare workers. Alex J Med 54(3): 273-277

20. Anand S, Mejid A (2018) Prevalence and associated factors of work related stress among nurses working in worabe comprehensive and specialized hospital, south west Ethiopia. Prevalence 3(3):260-266. https://www. researchgate.net/publication/328214011

21. Gillespie M, Melby V (2003) Burnout among nursing staff in accident and emergency and acute medicine: a comparative study. J clinl nurs 12(6):842-851

22. Mealer M, Jones J, Newman J, McFann KK, Rothbaum B, Moss M (2012) The presence of resilience is associated with a healthier psychological profile in intensive care unit (ICU) nurses: results of a national survey. Int J Nurs Stud 1;49(3):292-299.

23. Regan A, Howard RA, Oyebode JR (2009) Emotional exhaustion and defense mechanisms in intensive therapy unit nurses. J Nrvous Mental Dis 1;197(5): 330-336.

24. Poncet MC, Toullic P, Papazian L, Kentish-Barnes N, Timsit JF, Pochard F et al (2007) Burnout syndrome in critical care nursing staff. Am J Respir Crit Care Med 175(7):698-704

25. Verdon M, Merlani P, Perneger T, Ricou B (2008) Burnout in a surgical ICU team. Intens care med 1;34(1):152-6.

26. Dagget T, Molla A, Belachew T (2016) Job related stress among nurses working in Jimma Zone public hospitals, South West Ethiopia: a cross sectional study. BMC nursing 15(1):39

27. Teo ST, Yeung M, Chang E (2012) Administrative stressors and nursing job outcomes in Australian public and non-profit health care organisations. J Clin Nurs 21:1443-1452

28. Queiros C, Carlotto MS, Kaiseler M, Dias S, Pereira AM (2013) Predictors of burnout among nurses: an interactionist approach. Psicothema 25(3):330-335

29. Patrick K, Lavery JF (2007) Burnout in nursing. Austr J of Adv Nurs 24:43-48

30. Chang Y, Chan HJ (2015) Optimism and proactive coping in relation to burnout among nurses. J Nurs Manag 23(3):401-408

31. Borges-Garcia R (2010) Just grin and bear It?: proactive coping and PTSD in nursing students. Doctoral dissertation, Florida Atlantic University, Honors College

32. Lu DM, Sun N, Hong S, Fan YY, Kong FY, Li QJ (2015) Occupational stress and coping strategies among emergency department nurses of China. Archives psych nurs 29(4):208-212

\section{Publisher's Note}

Springer Nature remains neutral with regard to jurisdictional claims in published maps and institutional affiliations.

\section{Submit your manuscript to a SpringerOpen ${ }^{\circ}$ journal and benefit from:}

- Convenient online submission

- Rigorous peer review

- Open access: articles freely available online

- High visibility within the field

- Retaining the copyright to your article

Submit your next manuscript at $\boldsymbol{\nabla}$ springeropen.com 